\title{
Establishing a Standard of Care for Deep Brain Stimulation Centers in Canada
}

\author{
Michel Panisset, Marina Picillo, Nicolas Jodoin, Yu-Yan Poon, \\ Alejandro Valencia-Mizrachi, Alfonso Fasano, Renato Munhoz, Christopher R. Honey
}

\begin{abstract}
During the "DBS Canada Day" symposium held in Toronto July 4-5, 2014, the scientific committee invited experts to share their knowledge regarding deep brain stimulation (DBS) management of movement disorders in three domains: (1) the programming algorithms, (2) the necessary team to run a neurosurgery program, and (3) the appropriate scales to better define in a more comprehensive fashion the effect of the brain surgery. Each presentation was followed by an open discussion, and this article reports on the conclusions of this meeting on these three questions. Concerning programming, the role of the pulse width and the switching off of the stimulation at night for thalamic stimulation for the control of tremor have been discussed. The algorithms proposed in the literature for programming in Parkinson's disease (PD) need validation. In dystonia, the use of monopolar vs bipolar parameters, the use of low vs high frequencies and the use of smaller versus larger pulse widths all need to be examined properly. Concerning the necessary team to run a neurosurgical program, recommendations will follow the suggestions for standardized outcome measures. Regarding the outcome measures for DBS in PD, investigations need to focus on the non-motor aspects of PD. Identifying which nonmotor symptoms respond to DBS would allow a better screening before and satisfaction postoperatively. There is an important need for more data to determine the optimal programming protocol and the standard measures that should be performed routinely by all centers.
\end{abstract}

RÉSUMÉ: Établir des normes et des standards de qualité dans les centres de santé canadiens spécialisés en stimulation cérébrale profonde. C'est durant le symposium «Stimulation cérébrale profonde (SCP)-Fête du Canada » tenu à Toronto les 4 et 5 juillet 2014 qu'un comité scientifique a invité des experts à partager leurs connaissances en ce qui regarde trois aspects de la SCP en lien avec la prise en charge des troubles du mouvement : (1) la programmation d'algorithmes ; (2) le personnel nécessaire à la gestion d'un programme de neurochirurgie ; (3) les échelles adéquates pour mieux définir, de façon plus approfondie, les effets de la chirurgie du cerveau. Chaque présentation a ensuite été suivie d'un débat libre. Le but de cet article est donc d'offrir un compte rendu des conclusions de ce symposium quant aux trois aspects évoqués ci-dessus. En ce qui concerne la programmation, les participants ont abordé le rôle de la durée des impulsions ainsi que la mise à l'arrêt de la stimulation pendant la nuit au profit de la stimulation thalamique afin de contrôler les tremblements. En matière de programmation liée à la maladie de Parkinson (MP), les algorithmes qu'on retrouve dans la littérature scientifique doivent encore être validés. Lorsqu'il s'agit de la dystonie, l'utilisation de paramètres bipolaires ou unipolaires, de basses ou de hautes fréquences, et de durées d'impulsions plus petites ou plus grandes doit dans tous les cas être examinée attentivement. En ce qui regarde le personnel nécessaire à la gestion d'un programme de neurochirurgie, il est prévu que des recommandations s'inspirent de suggestions faites en faveur de mesures d'impact standardisées. En matière de mesures d'impact de la SCP en lien avec la MP, la recherche doit se concentrer sur les aspects non-moteurs de cette maladie. Le fait de déterminer les symptômes non-moteurs qui répondent à la SCP permettrait ainsi un meilleur dépistage initial ainsi qu'une meilleure satisfaction postopératoire. Enfin, il importe de compter sur plus de données afin d'établir un protocole de programmation optimal et de déterminer les normes et les standards de qualité qui devraient être adoptés de façon systématique par tous les centres de santé.

Keywords: Parkinson's disease, tremor, essential tremor, dystonia; deep brain stimulation, programming doi:10.1017/cjn.2016.409

Can J Neurol Sci. 2017; 44: 132-138

\section{INTRODUCTION}

Deep brain stimulation (DBS) is a well-established treatment of movement disorders. A significant amount of work has been done to set specific selection criteria to identify the patients who can obtain the best results from this treatment. Common DBS targets for movement disorders patients are the ventral intermediate nucleus of the thalamus (VIM), the globus pallidus pars interna (GPi), and the subthalamic nucleus (STN), but new targets such as the

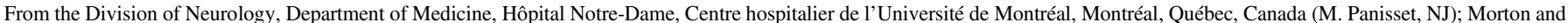

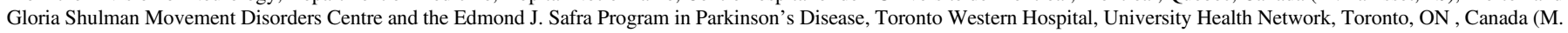

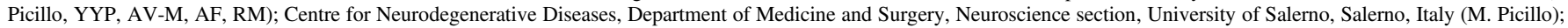

Division of Neurosurgery, University of British Columbia, Vancouver, British Columbia,Canada (CRH).

Received August 25, 2015. Date of Acceptance September 20, 2016.

Address correspondence to: Michel Panisset, CHUM - Hôpital Notre-Dame, Montréal, Québec, 1560, rue Sherbrooke Est, Montréal, Québec, H2L 4M1 Canada; e-mail: michel panisset@umontreal.ca. 
pedunculo-pontine nucleus are being investigated. Algorithms pertaining to the pharmacological interventions following surgeries still need to be established.

During the "DBS Canada Day" symposium held in Toronto July 4-5, 2014, the scientific committee invited experts to share their knowledge of target selection for DBS of patients with Parkinson's disease (PD). Experts were provided with selected topics for which they were asked to summarize the current literature and highlight what was known and what was still controversial within the field. The topics were divided into three questions.

In this article, we review the present knowledge and try to define the areas where more investigations are needed in three domains: (1) the programming algorithms, (2) the necessary team to run a neurosurgery program and (3) the appropriate scales to better define in a more comprehensive fashion the effect of the brain surgery.

One of the problems that we encountered is to differentiate between what was needed clinically to run a DBS program and what is used in larger academic centers for research purposes. For the three topics, a review of the literature was performed using the PubMed database from 1994 to 2014.

\section{The Programming Algorithms}

With the advance in imaging technology, electrophysiology recording techniques, and stimulation devices, we have the possibility to explore different DBS targets and stimulation parameters to maximize benefits and minimize side effects. In the following sections, we review the knowledge about programming for the different indications of DBS.

\section{TrEMOR}

VIM DBS for tremor was introduced in the 1980s; since then, different configurations and stimulation parameters have been used to improve tremor. Monopolar configuration remains most commonly used in DBS for tremor control. Using narrow pulse width $(60 \mu \mathrm{s})$ and a frequency of $130 \mathrm{~Hz}$, current intensity is increased progressively until tremor stops or until side effects are encountered. If tremor is not optimally controlled at 3.5 volts, pulse width and then the frequency of the stimulation can be increased. ${ }^{1}$ Paresthesia is the most common side effect because the created electrical field encroaches posteriorly in the thalamic sensory nucleus. It can be transient, lasting from few seconds to minutes, or permanent , and only resolved with stimulation intensity reduction. Other side effects include dystonia, ataxia, and dysarthria and depend on a number of factors including but not limited to the position of the electrode and the particular anatomy of the individual patient. Stimulation intensity required to suppress tremor is reduced as the stimulation field approaches the optimal stimulation site..$^{2-4}$

There are mixed results in the use of pulse width (60 vs $90 \mu \mathrm{s})$ for tremor relief. Increase of the pulse width results in reduction of amplitude threshold and increases the risk of side effects. In one publication with 11 subjects using different stimulation parameters, pulse width of $90 \mu$ s in bipolar mode was effective and well-tolerated. ${ }^{5}$

Patients with VIM DBS can be instructed to switch stimulation off at night to minimize battery usage. ${ }^{1}$ Also reported is a tolerance phenomenon or habituation to chronic VIM stimulation: this is the need to increase stimulation power to achieve tremor control. In one series, this occurred in $73 \%$ of essential tremor cases after a mean of 56 months postoperatively. ${ }^{6}$ Studies have attributed long-term stimulation failure to DBS tolerance, natural disease progression, or a combination of both. ${ }^{3,7-10}$ However, recent data would support a major role for disease progression and other factors including brain aging and atrophy. ${ }^{11}$

\section{Parkinson's Disease}

The use of DBS for PD began in the 1990s. Stimulation parameters of the STN to alleviate tremor, rigidity, and bradykinesia have been well-established. Moro et al studied 12 patients using 23 to 26 different monopolar stimulation settings in each patient. ${ }^{12}$ Stimulation amplitude of 3 volts and higher provided improvement in tremor, bradykinesia, and rigidity. Stimulation frequency of $50 \mathrm{~Hz}$ and $130 \mathrm{~Hz}$ improved tremor, rigidity, and bradykinesia. There was no significant improvement at $185 \mathrm{~Hz}$. High-pulse-width stimulation was poorly tolerated in this group of patients. Bradykinesia improved significantly only at $60 \mu \mathrm{s}$. No difference was noted in tremor with different pulse widths. Rigidity improved at higher pulse width (Table 1). In another paper, Moro et al evaluated the parameters of a series of 44 patients and reprogrammed them according to a standardized protocol: all patients' parameters were set at $60 \mu \mathrm{s}$ and $130 \mathrm{~Hz}$ and each contact were assessed at increasing amplitudes of 0.5 volts until side effects occurred. The final voltage was established either at a level lower than the side effect or dyskinesia threshold or at 3.6 volts. ${ }^{13}$ In the past, algorithms for initial programming and troubleshooting have been proposed as expert opinion, but have never been validated. ${ }^{14,15}$

Table 1: Effect of stimulation amplitude, frequency, and pulse width on rigidity, tremor, and bradykinesia (modified from Moro et al) ${ }^{12}$

\begin{tabular}{l|l|l|l|l}
\hline & & Rigidity & Tremor & Bradykinesia \\
\hline Amplitude & 3 volts & $\checkmark$ & $\checkmark$ & $\checkmark$ \\
\hline Frequency & $50 \mathrm{~Hz}$ & $\checkmark$ & $\checkmark$ \\
\hline & $130 \mathrm{~Hz}$ & $\checkmark$ & $\checkmark$ \\
\hline & $185 \mathrm{~Hz}$ & $\checkmark$ & No additional benefit & No additional benefit \\
\hline & $250 \mathrm{~Hz}$ & No additional benefit & No additional benefit \\
\hline Pulse width & $60 \mu \mathrm{s}$ & No additional benefit & $\checkmark$ \\
\hline
\end{tabular}


The incidence of dysarthria after bilateral STN DBS has been reported as high as $69.7 \% .^{16}$ Higher left STN voltage is associated with worse speech. ${ }^{17}$ One report suggested that high stimulation frequency and amplitude increased the risk of speech impairment. ${ }^{18}$ Another report suggested that high-frequency stimulation had a negative impact on speech-related velopharyngeal control. ${ }^{19}$

Axial symptoms such as postural instability and freezing of gait may worsen after STN DBS. ${ }^{20}$ The cause is most likely multifactorial: disease progression, medication reduction, cognitive decline, and stimulation-induced worsening. Low-frequency stimulation has been reported to be effective to improve gait and balance in a small group of patients, but this area remains controversial and deserves further investigation. ${ }^{21-24}$

\section{DYSTONIA}

GPi DBS has been applied worldwide as a surgical treatment alternative for medical refractory dystonia. The role of stimulation parameters on dystonic symptoms are not as well-established compared with PD and tremor. Unlike PD and tremor, for which the effect of stimulation is observed within seconds to minutes, the effect of GPi DBS on dystonia does not occur until hours, days, or in some cases even months. The Germany Dystonia Study Group proposes to use monopolar stimulation at $130 \mathrm{~Hz}$ and $120 \mu$ s and to increase the amplitude, testing for the acute effects. ${ }^{25}$ In terms of configuration of settings, no study is available comparing monopolar versus bipolar stimulation.

The use of high- versus low-frequency stimulation in dystonia has shown mixed results. Alterman et al suggested that the use of $60 \mathrm{~Hz}$ stimulation can be beneficial in some patients, ${ }^{26}$ whereas another group preferred high-frequency stimulation. ${ }^{27}$ Moro et al concluded that high amplitude and frequency stimulation predict better outcome in cervical dystonia. ${ }^{28}$

Various pulse widths have been recommended in GPi DBS for dystonia. Coubes et al recommend the use of $450 \mu \mathrm{s} .{ }^{29}$ However, another study comparing 60, 120, and $450 \mu$ s did not show significant difference among the three groups. ${ }^{30}$

Dystonia is a complex movement disorder with various etiologies, clinical manifestations, ages of onset, and genetic associations. Development of a stimulation algorithm addressing these issues should be considered.

The use of neuroimaging guided programming has been shown effective by Lee et al in PD. ${ }^{31}$ Further studies investigating the application of this technique in dystonia and tremor can be considered.

Advances in neurostimulation devices (implanted pulse generators) technology offers the options of current- versus voltage-controlled stimulation. One randomized controlled trial showed similar results between these two modes of stimulation, ${ }^{32}$ whereas a more recent open-label study found better outcomes with current-controlled stimulation. ${ }^{33}$

\section{CONClusion}

There is a major need for data in which each parameter is studied in a similar manner to what O'Suilleabhain et $\mathrm{al}^{5}$ have done so that we can have a better idea what the optimal amplitude, monopolar versus bipolar settings, pulse width, and frequency of stimulation we should aim for initially. It is clear that treatment will need to be individualized, but there may be parameters that are preferable in the majority of cases. Furthermore, technological advances are providing new possibilities for DBS programming. The use of interleaved settings may help in cases in which side effects precludes the use of standard parameters. ${ }^{34}$ The use of current-constant instead of voltage-constant stimulation may have some advantages, but studies on this topic are still needed. ${ }^{33}$ Mathematical modeling of stimulation is also a promising approach that is starting to be available and would give a boost to the spread of current steering stimulation. ${ }^{35}$ The available literature on DBS programming for PD, tremor, and dystonia has been recently reviewed and algorithms have been proposed to address specific patient's issues. ${ }^{36,37}$ Although useful, the proposed approaches have not been validated. ${ }^{38}$ By building a Canadian DBS network consisting of homogenous and comparable DBS teams, validation of such procedures may be significantly facilitated.

\section{BuILding A DBS TEAM}

The care of DBS patients can be divided into pre-, intra-, and post-DBS because there are different practitioners and interventions involved in all stages. We currently have clear guidelines for the presurgical evaluation of patients who are considered for DBS surgery, ${ }^{38}$ but there is no absolute consent regarding postsurgical management (i.e. who/when/how to perform DBS programming). Although several studies are available, ${ }^{39}$ there are no guidelines concerning the pharmacological modifications following surgery.

An expert consensus stated that for DBS teams to be effective, they should consist of dedicated neurologists, neurophysiologists, functional neurosurgeons, neuropsychologists, and nursing specialists. $^{40}$ It has also been reported that programming is best accomplished by highly trained clinicians in technical aspects of DBS as well as disease-related issues and pharmacological management. ${ }^{13,40-42}$ However, the guidelines and validated algorithms currently available do not cover all aspects of the programming needs, and troubleshooting is typically done based on personal experience and preferences.

The time spent in postoperative care and programming is an important factor to consider. As an example, at the University of Calgary, the required nursing programming time added up to 36 hours for postoperative care in the first year after surgery. ${ }^{42}$ The main factors influencing the time requirements are the expertise of each programmer ${ }^{13}$ and the time the team spent with patients before surgery. ${ }^{43}$

What is the team needed to run a DBS program? There is a wide variety of settings across Canada, ranging from minimal to extensive teams, depending on a number of factors including financial, academic interest, and personnel availabilities. Availability of expertise to fulfill the selection criteria for DBS needs to be mandatory. A movement disorder neurologist should assess candidates to ascertain the precise diagnosis. Other factors that influence the response to surgery such as age, motor status, cognitive functioning, social support, and expectations can be assessed and followed by a variety of discipline personal including neuropsychologists, psychiatrists, occupational therapists physiotherapists, social workers, and nurses, but the need for specific professional personnel is not demonstrated. It also needs to be clear how much personnel is needed depending on the DBS center orientation, be it predominantly care or academic work.

By creating a Canadian DBS network, the minimal personnel required to run an efficient service may be better established and 
features distinguishing care or academic centers may be delineated. Furthermore, by comparing the different experiences coming from each DBS team throughout the country, it would be also possible to point which is the added value of each specific professional personnel when available (e.g. social workers).

\section{Outcome Measures for DBS IN PD: When}

Preoperative evaluation of candidates should probably be done in the 3 months preceding surgery. The timing of the postoperative assessment should take into account some of the following factors: the placebo effect after months of waiting for the intervention, the microlesion effect of lead insertion that can last for as long as 3 months after surgery, and the time for obtaining the full effect after adjustment of stimulation parameters and medication that can take from 3 to 6 months (and even longer in some patients). In that context, postoperative evaluation should probably be performed about 6 months to 1 year after the surgery. Longer term follow-up is possibly influenced by the progression of the disease. ${ }^{44}$

\section{Outcome Measures for DBS in PD: What}

Quantifiable outcome measures are needed to further refine the clinical criteria used to select patients, to detect potential side effects and find solutions to prevent them in the future, to allow comparison between groups (benchmarking), and, in the end, to improve the quality of care. Outcome measures need to be clinically meaningful, especially for patients, and adapted to the clinical context.

Because PD is a complex disease that is also characterized by neuropsychiatric symptoms with significant social impact, measures evaluating cognition and behavior are fundamental. Nondopaminergic motor and nonmotor symptoms of PD that are major determinants of the quality of life of patients are rarely helped by DBS, but may even represent contraindications for DBS (e.g. depression, dementia). ${ }^{45,46}$ Some symptoms, such as speech, may be worsened with STN DBS. Nonmotor manifestations of PD include symptoms related to dopaminergic deficit (such as depression, anxiety, pain, and apathy) or to a hyperdopaminergic state (including impulse control disorders, punding, and dopamine dysregulation syndrome). ${ }^{45}$ Despite a significant improvement in motor symptoms of PD, many patients seem dissatisfied with the results of surgery and do not return to a functional psychosocial level. ${ }^{47}$ Indeed, DBS mainly improves motor aspects of $\mathrm{PD},{ }^{48}$ but the patients' satisfaction after DBS seems to be greatly influenced by nonmotor factors such as depression and apathy and by expectation management. ${ }^{49,50}$

Most of the work in the field of outcome measures has focused for many years on identifying patients who may benefit from DBS, while ensuring neuropsychiatric safety. ${ }^{51}$ The Core Assessment Program for Surgical Interventional Therapies in Parkinson's Disease protocol has been used extensively. ${ }^{52}$ Studies have mainly focused on the Unified Parkinson's disease rating scale (UDPRS) activities of daily living and motor score on and off medication as the primary outcome measure. Motor complications, including fluctuations and dyskinesias, are evaluated with UDPRS part IV or patients diaries. ${ }^{53}$ Some studies used additional motor assessments with timed motor tasks (e.g. bradykinesia, walking). Changes in levodopa-equivalent daily doses are reported using standardized conversion formula. ${ }^{54}$

\section{Table 2: Recommended outcome measures}

\begin{tabular}{|c|c|c|}
\hline Outcome measure & Scale & Reference \\
\hline Activities of daily living & $\begin{array}{l}\text { UPDRS II } \\
\text { During worst condition (Med } \\
\text { OFF/Stim ON vs Med OFF) }\end{array}$ & Fahn, 1987 \\
\hline \multirow[t]{2}{*}{ Motor disability } & UPDRS III off medication & Fahn, 1987 \\
\hline & MDS-UPDRS & Goetz, 2008 \\
\hline $\begin{array}{l}\text { Levodopa-related } \\
\text { complications }\end{array}$ & UPDRS IV & Fahn, 1987 \\
\hline Disease stage & Hoehn and Yahr & Hoehn, 1967 \\
\hline Functional level & Schwab and England & Schwab, 1969 \\
\hline $\begin{array}{l}\text { Levodopa-equivalent } \\
\text { dosage }\end{array}$ & & Tomlinson, 2010 \\
\hline \multirow[t]{2}{*}{ Global cognitive function } & $\begin{array}{l}\text { Mattis dementia rating } \\
\text { scale }\end{array}$ & Mattis, 1976 \\
\hline & $\begin{array}{l}\text { Montreal Cognitive } \\
\text { assessment }\end{array}$ & Nasreddine, 2005 \\
\hline \multirow[t]{3}{*}{$\begin{array}{l}\text { Global behavioral } \\
\text { assessments }\end{array}$} & $\begin{array}{l}\text { Mini-International } \\
\text { Neuropsychiatric Interview }\end{array}$ & Sheehan, 1998 \\
\hline & Neuropsychiatric Inventory & Cummings, 1994 \\
\hline & $\begin{array}{l}\text { Brief Psychiatric Rating } \\
\text { Scale }\end{array}$ & Overall, 1962 \\
\hline \multirow[t]{3}{*}{ Depression } & $\begin{array}{l}\text { Montgomery and Asberg } \\
\text { Depression Rating Scale }\end{array}$ & Montgomery, 1979 \\
\hline & $\begin{array}{l}\text { Hamilton Depression } \\
\text { Rating Scale }\end{array}$ & Hamilton, 1960 \\
\hline & Beck Depression Inventory & Beck, 1961 \\
\hline \multirow[t]{3}{*}{ Anxiety } & Hamilton Anxiety Rating Scale & Hamilton, 1959 \\
\hline & Beck Anxiety Inventory & Beck, 1988 \\
\hline & $\begin{array}{l}\text { State and Trait Anxiety } \\
\text { Inventory }\end{array}$ & Spielberger, 1983 \\
\hline \multirow[t]{2}{*}{ Apathy } & Apathy Inventory & Robert, 2002 \\
\hline & Apathy Scale & Starkstein, 1992 \\
\hline \multirow[t]{2}{*}{ Quality of life } & PDQ-39 (summary index) & Peto, 1995 \\
\hline & SF-36 & Ware, 1992 \\
\hline Social adjustment & Social Adjustment Scale & Mundt, 2002 \\
\hline Caregiver burden & Zarit Burden Inventory & Zarit, 1980 \\
\hline Psychosocial functioning & SCOPA-PS & Marinus, 2003 \\
\hline
\end{tabular}

Med = Medication; SCOPA-PS $=$ The Scales for Outcomes in

Parkinson's disease-PsychoSocial questionnaire; SF-36 = 36-item Short Form; Stim $=$ Stimulation.

In recent years, the focus of outcome measures has shifted from objective motor parameters to more subjective indicators, including evaluation of quality of life and caregiver burden. For example, some studies have chosen to use a quality of life scale, such as the 39-item Parkinson's disease Questionnaire (PDQ-39), a disease-specific instrument validated for the assessment of health-related quality of life of PD patients, as the primary criterion of analysis. ${ }^{55}$

In terms of nondopaminergic symptoms, subscores of the UPDRS scale can be used to evaluate the change in speech or gait, but specific scales are probably more useful and can provide a more detailed evaluation. ${ }^{56}$ The new Movement Disorders 
Society version of the UPDRS (MDS-UPDRS) could accurately track motor and nonmotor changes occurring after DBS. ${ }^{57,58}$ Many validated scales for nonmotor symptoms of PD have been developed in recent years. ${ }^{59-75}$

Although the UPDRS and the newer MDS-UPDRS are the cornerstones of the motor evaluation of PD patients, a significant amount of work is warranted to establish the best scales to evaluate both the nonmotor symptoms and quality of life. There is a need for a consensus, similar to the recommendations on the minimum criteria for studies reporting on DBS in $\mathrm{PD},{ }^{76}$ on the scales to be used so that comparison and pooling of data between centers can be performed (Table 2). A similar list of scales could be obtained from the Committee of Rating Scales Development of The Movement Disorders Society (http://www. movementdisorders.org/MDS/About/Committees-Other-Groups/ MDS-Committees/Committee-on-Rating-Scales-Development. htm). Recommendations coming from a committee formed by experts and patients would be welcome.

Establishing a Canadian DBS network would boost the initiation of multicenter studies for the comparison and validation of the previously mentioned scales in DBS patients; the work would be significantly facilitated as a greater amount of patients would be available in a short time and both research and clinical centers might be involved.

\section{Conclusion}

It is clear from the information we have gathered here that there is a great need for more data to determine the optimal programming protocol and the standard measures that should be performed routinely by all centers.

Presently, there are no validated algorithms to guide clinicians with their programming. Studies are needed to look at optimal timing for initial programming, the use of anatomical versus electrophysiological strategies for target localization, and the correct stimulation settings to address patients' symptoms without causing side effects.

There is a great deal of variability across centers in the composition of the DBS teams - from a few-member team to a full deck of nurses, speech therapists, physiotherapists, occupational therapists, psychologists, social workers, psychiatrists, physiologists, neurologists, and neurosurgeons. There is probably no need to have all these personnel for a program to run efficiently and safely and it is probably unrealistic to think that all DBS programs would be entitled to this type of team on a financial basis. These large teams are nevertheless important for academic centers to study different aspects of DBS treatment. Establishing a minimum number of personnel to run a program would nevertheless raise the important question of how to support these programs across the country.

For PD, most studies looked at motor outcomes such as the UPDRS. A smaller number of studies have looked at nonmotor aspects of the disease or at more specific motor outcomes, such as speech and gait. Rare studies looked at the psychosocial aspect, where many questions are still unanswered. What impact does DBS have on the patient's spouse, family, and social environment? Why do we sometimes end up in a situation in which the patient feels this surgery was not the hoped-for success whilst the professional team feels the results of the surgery were optimal? These questions are very important because they affect the functional outcome of DBS and the patient's return to a more normal life. ${ }^{46}$
We hope our work will be the start for a coordinated work amongst DBS centers to answer the various questions it raised.

\section{ACKNOWLEDGEMENTS}

This review is the product of the comprehensive and enlightening discussion between Canadian DBS experts occurred during the 'DBS Canada Days', held in Toronto on July 4-5 2014.

\section{Disclosures}

The DBS Canada Days symposium was sponsored by Medtronic and all speakers received honoraria and necessary transportation and accommodation. The final report provided has no industry-specific recommendations and was carefully screened to avoid any potential bias.

Michel Panisset, Yu-Yan Poon, Renato Munhoz, and Alejandro Valencia-Mizrachi do not have anything to disclose.

Christopher Honey has the following disclosures: Medtronic, Speaker's fees, Honoraria; Metronic, Consultant, Consulting fees.

Alfonso Fasano has the following disclosures: Abbvie, Consultant, Consulting fees; Abbvie, Advisor, Honoraria; Boston Scientific, Consultant, Consulting fees; Boston Scientific, Advisor, Honoraria; Metronic, Consultant, Consulting fees; Metronic, Advisor, Honoraria; Metronic, Research support; TEVA Canada, Consultant, Consulting fees; TEVA Canada, Advisor, Honoraria; Novartis, Consultant, Consulting fees; Novartis, Advisor, Honoraria; UCB Pharma, Consultant, Consulting fees; UCB Pharma, Advisor, Honoraria.

Nicolas Jodoin has the following disclosures: Abbvie, Consultant, Consulting fees; Medtronic, Speaker, Speaker's fees.

\section{REFERENCES}

1. Dowsey-Limousin P. Postoperative management of Vim DBS for tremor. Mov Disord. 2002;17:S208-11.

2. Benabid AL, Pollak P, Gervason C, et al. Long-term suppression of tremor by chronic stimulation of the ventral intermediate thalamic nucleus. Lancet. 1991;337:403-6.

3. Benabid AL, Pollak P, Gao D, et al. Chronic electrical stimulation of the ventralis intermedius nucleus of the thalamus as a treatment of movement disorders. J Neurosurg. 1996;84:203-14.

4. Koller W, Pahwa R, Busenbark K, et al. High-frequency unilateral thalamic stimulation in the treatment of essential and parkinsonian tremor. Ann Neurol. 1997;42(3):292-9.

5. O'Suilleabhain PE, Frawley W, Giller C, Dewey RB Jr. Tremor response to polarity, voltage, pulsewidth and frequency of thalamic stimulation. Neurology. 2003;60:786-90.

6. Shih LC, LaFaver K, Lim C, et al. Loss of benefit in VIM thalamic deep brain stimulation (DBS) for essential tremor (ET): how prevalent is it? Parkinsonism Relat Disord. 2013;19:676-9.

7. Limousin P, Speelman JD, Gielen F, Janssens M. Multicentre European study of thalamic stimulation in parkinsonian and essential tremor. $\mathrm{J}$ Neurol Neurosurg Psychiatry. 1999;66:289-96.

8. Hariz MI, Shamsgovara P, Johansson F, et al. Tolerance and tremor rebound following long-term chronic thalamic stimulation for Parkinsonian and essential tremor. Stereotact Funct Neurosurg. 1999;72:208-18.

9. Koller WC, Lyons KE, Wilkinson SB, Troster AI, Pahwa R. Long-term safety and efficacy of unilateral deep brain stimulation of the thalamus in essential tremor. Mov Disord. 2001;16:464-8.

10. Garcia Ruiz P, Muñiz de Igneson J, Lopez Ferro O, Martin C, Magariños Ascone C. Deep brain stimulation holidays in essential tremor. J Neurol. 2001;248:725-6. 
11. Favilla CG, Ullman D, Wagle Shukla A, et al. Worsening essential tremor following deep brain stimulation: disease progression versus tolerance. Brain. 2012;135:1455-62.

12. Moro E, Esselink RJ, Xie J, et al. The impact on Parkinson's disease of electrical parameter settings in STN stimulation. Neurology. 2002;59:706-13.

13. Moro E, Poon Y-Y W, Lozano AM, Saint-Cyr JA, Lang AE. Subthalamic nucleus stimulation. Improvements in outcome with reprogramming. Arch Neurol. 2006;63:1266-72.

14. Volkmann J, Herzog J, Kopper F, Deuschl G. Introduction to the programming of deep brain stimulators. Mov Disord. 2002; 17(Suppl 3):S181-7.

15. Volkmann J, Moro E, Pahwa R. Basic algorithms for the programming of deep brain stimulation in Parkinson's disease. Mov Disord. 2006;21(Suppl 14):S284-9.

16. Piboolnurak P, Lang AE, Lozano AM, et al. Levodopa response in long-term bilateral subthalamic stimulation for Parkinson's disease. Mov Disord. 2007;22:990-7.

17. Tripoliti E, Zrinzo L, Martinez-Torres I, et al. Effects of subthalamic stimulation on speech of consecutive patients with Parkinson disease. Neurology. 2011;76:80-6.

18. Törnqvist AL, Schalén L, Rehncrona S. Effects of different electrical parameter settings on the intelligibility of speech in patients with Parkinson's disease treated with subthalamic deep brain stimulation. Mov Disord. 2005;20:416-23.

19. Hammer MJ, Barlow SM, Lyons KE, Pahwa R. Subthalamic nucleus deep brain stimulation changes velopharyngeal control in Parkinson's disease. J Commun Disord. 2011;44:37-48.

20. Collomb-Clerc A, Welter ML. Effects of deep brain stimulation on balance and gait in patients with Parkinson's disease: a systematic neurophysiological review. Clin Neurophys. 2015;45:371-88.

21. Moreau C, Defebvre L, Destée A, et al. STN-DBS frequency effects on freezing of gait in advanced Parkinson disease. Neurology. 2008;71:80-4.

22. Khoo HM, Kishima H, Hosomi K, et al. Low-frequency subthalamic nucleus stimulation in Parkinson's disease: a randomized clinical trial. Mov Disord. 2014;29:270-4.

23. Sidiropoulos C, Walsh R, Meaney C, et al. Low-frequency subthalamic nucleus deep brain stimulation for axial symptoms in advanced Parkinson's disease. J Neurol. 2013;260:2306-11.

24. Zibetti M, Moro E, Krishna V, et al. Low-frequency subthalamic stimulation in Parkinson's disease: long-term outcome and predictors. Brain Stim. 2016;9:774-9.

25. Kupsch A, Benecke R, Müller J, et al. Deep-Brain Stimulation for Dystonia Study Group. Pallidal deep-brain stimulation in primary generalized or segmental dystonia. N Engl J Med. 2006;355:1978-90.

26. Alterman RL, Shils JL, Miravite J, Tagliati M. Lower stimulation frequency can enhance tolerability and efficacy of pallidal deep brain stimulation for dystonia. Mov Disord. 2007;22:366-8.

27. Kupsch A, Klaffke S, Kühn AA, et al. The effects of frequency in pallidal deep brain stimulation for primary dystonia. J Neurol. 2003;250:1201-5; Erratum in: J Neurol. 2004;251:1031.

28. Moro E, Piboolnurak P, Arenovich T, Hung SW, Poon YY, Lozano AM. Pallidal stimulation in cervical dystonia: clinical implications of acute changes in stimulation parameters. Eur $\mathbf{J}$ Neurol. 2009;16:506-12.

29. Coubes P, Cif L, El Fertit H, Hemm S, et al. Electrical stimulation of the globus pallidus internus in patients with primary generalized dystonia: long-term results. J Neurosurg. 2004;101:189-94.

30. Vercueil L, Houeto JL, Krystkowiak P, et al. Effects of pulse width variations in pallidal stimulation for primary generalized dystonia. J Neurol. 2007;254:1533-7.

31. Lee JY, Jeon BS, Paek SH, et al. Reprogramming guided by the fused images of MRI and CT in subthalamic nucleus stimulation in Parkinson disease. Clin Neurol Neurosurg. 2010;112:47-53.

32. Okun MS, Gallo BV, Mandybur G, et al. Subthalamic deep brain stimulation with a constant-current device in Parkinson's disease: an open-label randomised controlled trial. Lancet Neurol. 2012;11:140-9.

33. Lettieri C, Rinaldo S, Devigili G, et al. Clinical outcome of deep brain stimulation for dystonia: constant-current or constantvoltage stimulation? A non-randomized study. Eur J Neurol. $2015 ; 22: 919-26$.
34. Ramirez-Zamora A, Kahn M, Campbell J, et al. Interleaved programming of subthalamic deep brain stimulation to avoid adverse effects and preserve motor benefit in Parkinson's disease. J Neurol. 2105;262:578-84.

35. McIntyre CC, Frankenmolle A, Wu J, et al. Customizing deep brain stimulation to the patient using computational models. Conf Proc IEEE Eng Med Biol Soc. 2009;2009:4228-9.

36. Picillo M, Lozano AM, Kou N, Puppi Munhoz R, Fasano A. Programming deep brain stimulation for Parkinson's disease: the Toronto Western Hospital Algorithms. Brain Stimul. 2016;9:425-37.

37. Picillo M, Lozano AM, Kou N, Munhoz RP, Fasano A. Programming Deep Brain Stimulation for Tremor and Dystonia: The Toronto Western Hospital Algorithms. Brain Stimul. 2016 May-Jun;9(3):438-52.

38. Bronstein JM, Tagliati M, Alterman RL, et al. Deep brain stimulation for Parkinson disease: an expert consensus and review of key issues. Arch Neurol. 2011;68:165-71.

39. Fasano A, Appel-Cresswell S, Jog M, et al. Medical management of Parkinson's disease after initiation of deep brain stimulation. Can J Neurol Sci. 2016;43:626-34.

40. Castrioto A, Volkmann J, Krack P. Postoperative management of deep brain stimulation in Parkinson's disease. Handb Clin Neurol. 2013;116:129-46.

41 Chan DTM, Zhu XL, Yeung J, et al. Complications of deep brain stimulation: a collective review. Asian J Surg. 2009;32:258-63.

42. Hunka K, Suchowersky O, Wood S, et al. Nursing time to program and assess deep brain stimulators in movement disorder patients. J Neurosci Nurs. 2005;37:204-10.

43. Bel E, Maxwell B, McAndrews MP, et al. Deep brain stimulation and ethics: perspectives from a multisite qualitative study of Canadian neurosurgical centers. World Neurosurg. 2011;6:537-47.

44. Rodriguez-Oroz MC, Moro E, Krack P. Long-term outcomes of surgical therapies for Parkinson's disease. Mov Disord. 2012;27:1718-28.

45. Castrioto A, Lhommée E, Moro E, Krack P. Mood and behavioural effects of subthalamic stimulation in Parkinson's disease. Lancet Neurol. 2014;13:287-305.

46. Fasano A, Daniele A, Albanese A. Treatment of motor and nonmotor features of Parkinson's disease with deep brain stimulation. Lancet Neurol. 2012;11:429-42.

47. Schüpbach M, Gargiulo M, Welter ML, Mallet L, et al. Neurosurgery in Parkinson disease: a distressed mind in a repaired body? Neurology. 2006;66:1811-6.

48. Drapier S, Raoul S, Drapier D, et al. Only physical aspects of quality of life are significantly improved by bilateral subthalamic stimulation in Parkinson's disease. J Neurol. 2005;252:583-8

49. Maier F, Lewis CJ, Horstkoetter N, et al. Patients' expectations of deep brain stimulation, and subjective perceived outcome related to clinical measures in Parkinson's disease: a mixed-method approach. J NeurolNeurosurg Psychiatry. 2013;84 (11):1273-81

50. Hasegawa H, Samuel M, Douiri A, Ashkan K. Patients' expectations in subthalamic nucleus deep brain stimulation surgery for Parkinson disease. World Neurosurg. 2014;82:1295-9.

51. Lang AE, Houeto JL, Krack P, et al. Deep brain stimulation: preoperative issues. Mov Disord. 2006;21(Suppl. 14):S171-96.

52. Defer GL, Widner H, Marié RM, et al. Core assessment program for surgical interventional therapies in Parkinson's disease (CAPSIT-PD). Mov Disord. 1999;14:572-84.

53. Fahn S, Elton RL, UPDRS Program Members. Unified Parkinson's disease rating scale. In: Fahn S, Marsden CD, Goldstein M, Calne DB, editors. Recent developments in Parkinson's disease, Vol. 2. Florham Park, NJ: Macmillan Healthcare Information; 1987, p. $153-63 ; 293-304$

54. Tomlinson CL, Stowe R, Patel S, et al. Systematic review of levodopa dose equivalency reporting in Parkinson's disease. Mov Disord. 2010;25:2649-53.

55. Peto V, Jenkinson C, Fitzpatrick R, Greenhall R. The development and validation of a short measure of functioning and well-being for individuals with Parkinson's disease. Qual Life Res. $1995 ; 4: 241-8$. 
56. St George RJ, Carlson-Kuhta P, Nutt JG, et al. The effect of deep brain stimulation randomized by site on balance in Parkinson's disease. Mov Disord. 2014;29:949-53.

57. Goetz CG, Tilley BC, Shaftman SR, et al. Movement Disorder Society-sponsored revision of the Unified Parkinson's Disease Rating Scale (MDS-UPDRS): scale presentation and clinimetric testing results. Mov Disord. 2008;23:2129-70.

58. Chou KL, Taylor JL, Patil PG. The MDS-UPDRS tracks motor and non-motor improvement due to subthalamic nucleus deep brain stimulation in Parkinson disease. Parkinsonism Relat Disord. 2013;19:966-9.

59. Mattis S. Mental status examination for organic mental syndrome in the elderly patients. In: Bellak L, Karasu T, editors. Geriatrics psychiatry: a handbook for psychiatrists and primary care physicians. New York: Grune \& Stratton; 1976, p. 77-121.

60. Nasreddine ZS, Phillips NA, Bedirian V, et al. The Montreal Cognitive Assessment, MoCA: a brief screening tool for mild cognitive impairment. J Am Geriatr Soc. 2005;53:695-9.

61. Sheehan DV, Lecrubier Y, Sheehan KH, et al. The Mini-International Neuropsychiatric Interview (M.I.N.I.): the development and validation of a structured diagnostic psychiatric interview for DSM-IV and ICD-10. J Clin Psychiatry. 1998;59(suppl 20): 22-33.

62. Cummings J, Mega M, Gray K, et al. The Neuropsychiatric Inventory: comprehensive assessment of psychopathology in dementia. Neurology. 1994;44:2308-14.

63. Overall JE, Gorham DR. The brief psychiatric rating scale. Psychol Rep. 1962;10:799-812.

64. Montgomery SA, Asberg M. A new depression scale designed to be sensitive to change. Br J Psychiatry. 1979;134:382-9.

65. Hamilton M. A rating scale for depression. J Neurol Neurosurg Psychiatry. 1960;23:56-62.
66. Beck AT, Ward CH, Mendelson M, et al. An inventory for measuring depression. Arch Gen Psychiatry. 1961;4:561-71.

67. Hamilton M. The assessment of anxiety states by rating. Br J Med Psychol. 1959;32:50-5.

68. Beck AT, Epstein N, Brown G, Steer RA. An inventory for measuring clinical anxiety: psychometric properties. J Consult Clin Psychology. 1988;56:893-7.

69. Spielberger CD, Gorsuch RL, Lushene R, Vagg PR, Jacobs GA. Manual for the State-Trait Anxiety Inventory. Palo Alto, CA: Consulting Psychologists Press; 1983.

70. Robert PH, Clairet S, Benoit M, et al. The apathy inventory: assessment of apathy and awareness in Alzheimer's disease, Parkinson's disease and mild cognitive impairment. Int J Geriatr Psychiatry. 2002;17:1099-105.

71. Starkstein SE, Mayberg HS, Preziosi TJ, et al. Reliability, validity, and clinical correlates of apathy in Parkinson's disease. J Neuropsychiatry Clin Neurosci. 1992;4:134-9.

72. Ware JE Jr, Sherbourne CD. The MOS 36-item short-form health survey (SF-36). Conceptual framework and item selection. Med Care. 1992;30:473-83.

73. Mundt JC, Marks IM, Shear MK, Greist JH. The Work and Social Adjustment Scale: a simple measure of impairment in functioning. Br J Psychiatry. 2002;180:461-4.

74. Zarit SH, Reever KE, Back-Peterson J. Relatives of the impaired elderly: correlates of feelings of burden. Gerontologist. 1980;20:649-55.

75. Marinus J, Visser M, Martínez-Martín P, et al. A short psychosocial questionnaire for patients with Parkinson's disease: the SCOPA-PS. J Clin Epidemiol. 2003;56:61-7.

76. Vitek JL, Lyons KE, Bakay R, et al. Standard guidelines for publication of deep brain stimulation studies in Parkinson's disease (Guide4DBS-PD). Mov Disord. 2010;25:1530-7. 